\title{
LAS RUTAS DE LOS CENTROAMERICANOS POR MÉXICO, UN EJERCICIO DE CARACTERIZACIÓN, ACTORES PRINCIPALES Y COMPLEJIDADES
}

RODOLFO CASILLAS R. ${ }^{1}$

\section{INTRODUCCIÓN}

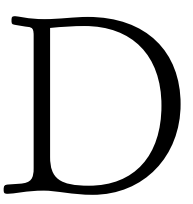
urante los últimos años se ha señalado que el flujo migratorio centroamericano que pasa por México con destino a Estados Unidos mantiene un crecimiento constante. También se ha dicho que cada vez es mayor el porcentaje de mujeres, adolescentes, niñas y niños que engrosan ese flujo. Pese a las distintas medidas de las autoridades migratorias para tratar de controlarla, la transmigración centroamericana sigue su marcha y engrosamiento, aunque circunstancialmente afectada por los huracanes y otros desastres climáticos que desde finales del 2005 en adelante han dañado las vías públicas de comunicación, particularmente en algunos lugares estratégicos del sur-sureste mexicano.

Mientras las viejas carencias y limitaciones de los esquemas socioeconómicos centroamericanos siguen alentando la emigración y el envío de remesas desde Estados Unidos, el paso por México se vuelve cada vez más importante para los transmigrantes, para los limitados círculos sociales que les apoyan, para las crecientes organizaciones delictivas que con ellos lucran, para las instituciones bancarias y su ampliada red de servicios financieros y para las inconsistentes instancias públicas que procuran que la migración internacional ocurra conforme a las disposiciones legales correspondientes. Consideraciones de seguridad nacional, combate al tráfico de drogas, a la trata de personas y, con menores perspectivas, de fomento al comercio con países del Istmo centroamericano y la reglamentación de un mercado laboral regional del sur de México con Guatemala y Belice forman parte del

\footnotetext{
${ }^{1}$ Profesor e investigador de la Facultad Latinoamericana de Ciencias Sociales, sede académica de México, correos electrónicos: casillas@flacso.edu.mx y casillassan@gmail.com
} 
espectro migratorio actual. Este conjunto de diversos intereses, participaciones y expectativas muestran la existencia concurrente y simultánea de procesos sociales e institucionales diferentes para los cuales no hay respuestas únicas ni tiempos únicos de respuesta. Lo que ocurra en los tiempos venideros tendrá que tomar en cuenta esta diversidad de eventos en el espacio de tránsito mexicano y, en particular, por las rutas migratorias que vinculan las ilusiones del sur con las realidades del norte. ${ }^{2}$ De ese transitar, sus actores principales, peripecias, solidaridades, dramas y abusos se da cuenta en el presente artículo.

\section{DEL PORQUÉ SE MULTIPLICAN LAS RUTAS}

A ciencia cierta, no hay manera de demostrar estadísticamente que el flujo transmigratorio centroamericano ha crecido y sigue creciendo; tampoco hay manera de demostrar que ha decrecido. En ambos extremos hay apreciaciones, en buena parte producto del valor relativo de agentes institucionales y sociales diversos con sus condicionamientos de lugar, participación, interés, perspectiva y acceso a expresiones específicas, directas o no, de los flujos migratorios bajo observación. La razón principal es que casi en su totalidad los transmigrantes centroamericanos transitan por México sin la visa correspondiente, es decir lo hacen de manera indocumentada. De ahí que se cuente con apreciaciones y deducciones indirectas de algunos registros de organismos civiles y de instancias oficiales, como son los producidos por el Instituto Nacional de Migración (INM). La fuente más citada se refiere al total de eventos de detenciones (o aseguramientos como se conceptualiza en el argot oficial), con las características que a continuación se presentan.

\section{CUADRO 1}

Eventos de aseguramiento de extranjeros indocumentados en México por nacionalidad, Instituto Nacional de Migración, 2001-2007

\begin{tabular}{|c|c|c|c|c|c|c|c|c|c|c|c|c|c|}
\hline \multirow{2}{*}{ AÑO } & \multicolumn{2}{|c|}{ GUATEMALTECA } & \multicolumn{2}{|c|}{ HONDUREÑA } & \multicolumn{2}{|c|}{ SALVADOREÑA } & \multicolumn{2}{|c|}{ NICARAGÜENSE } & \multicolumn{2}{|c|}{ OTRAS } & \multicolumn{3}{|c|}{ TOTAL } \\
\cline { 2 - 14 } & \multicolumn{1}{|c|}{ TOTAL } & $\%$ & \multicolumn{1}{c|}{ TOTAL } & $\%$ & \multicolumn{1}{c|}{ TOTAL } & $\%$ & TOTAL & $\%$ & TOTAL & $\%$ & TOTAL & $\%$ \\
\hline 2001 & 67,522 & 44.9 & 40,105 & 26.6 & 35,007 & 23.3 & 1,712 & 1.1 & 6,184 & 4.1 & 150,530 & 100.0 \\
\hline 2002 & 67,336 & 48.8 & 41,801 & 30.3 & 20,800 & 15.1 & 1,609 & 1.2 & 6,515 & 4.6 & 138,061 & 100.0 \\
\hline 2003 & 86,023 & 45.9 & 61,900 & 33.0 & 29,301 & 15.6 & 2,150 & 1.1 & 8,240 & 4.4 & 187,614 & 100.0 \\
\hline 2004 & 94,404 & 43.8 & 72,684 & 33.7 & 34,572 & 16.0 & 2,453 & 1.1 & 11,582 & 5.4 & 215,695 & 100.0 \\
\hline 2005 & 100,948 & 41.0 & 78,326 & 33.0 & 42,674 & 18.0 & 3,980 & 2.0 & 14,341 & 6.0 & 240,269 & 100.0 \\
\hline 2006 & 84,523 & 46.3 & 58,001 & 31.7 & 27,287 & 14.9 & 3,590 & 2.0 & 9,304 & 5.1 & 182,705 & 100.0 \\
\hline 2007 & 15,143 & 29.9 & 22,989 & 45.4 & 5,837 & 11.5 & 862 & 1.7 & 5,767 & 11.5 & 50,598 & 100.0 \\
\hline
\end{tabular}

Fuente: Elaboración propia basada en Datos estadísticos migratorios de México, Instituto Nacional de Migración.

${ }^{2}$ Con el patrocinio del Fondo Sectorial Segob-Conacyt, se efectuó, de agosto de 2005 a diciembre de 2006, el proyecto de investigación titulado «Presente y futuro de los transmigrantes centroame- 
Las principales nacionalidades que engrosan el total de extranjeros indocumentados detenidos por el INM son la guatemalteca, hondureña, salvadoreña y nicaragüense, en ese orden decreciente. Así lo fue a finales del siglo xx y al inicio del xxI esta tendencia se mantiene constante. De hecho, esas nacionalidades ya se mantenían como tales desde los años 90, cuando las autoridades migratorias de México incrementaron su labor de contención de la migración indocumentada, como se muestra en el cuadro siguiente.

\section{CUADRO 2}

Devoluciones y rechazos de extranjeros de México por nacionalidad, Instituto Nacional de Migración, 1990-2000

\begin{tabular}{|c|c|c|c|c|c|c|c|}
\hline & \multicolumn{5}{|c|}{ NACIONALIDAD } & & \\
\hline AÑO & GUATEMALTECA & SALVADOREÑA & HONDUREÑA & NICARAGÜENSE & OTRAS & TOTAL \% & TOTAL ABSOLUTOS \\
\hline 1990 & 46.5 & 36.1 & 11.8 & 2.4 & 3.2 & 100 & 126,440 \\
\hline 1991 & 52.5 & 30.3 & 13.8 & 0.9 & 2.4 & 100 & 133,342 \\
\hline 1992 & 53.1 & 21.7 & 20.8 & 1.4 & 3.1 & 100 & 123,046 \\
\hline 1993 & 48.3 & 23.5 & 21.9 & 2.8 & 3.5 & 100 & 122,005 \\
\hline 1994 & 38.0 & 20.2 & 28.7 & 10.9 & 2.3 & 100 & 113,115 \\
\hline 1995 & 49.1 & 18.4 & 25.7 & 2.4 & 4.3 & 100 & 105,940 \\
\hline 1996 & 47.1 & 19.5 & 29.0 & 1.8 & 2.6 & 100 & 107,118 \\
\hline 1997 & 44.2 & 22.0 & 29.1 & 1.4 & 3.3 & 100 & 85,588 \\
\hline 1998 & 41.3 & 23.1 & 31.5 & 1.7 & 2.4 & 100 & 111,572 \\
\hline 1999 & 40.3 & 20.7 & 25.4 & 1.1 & 2.5 & 100 & 126,498 \\
\hline 2000 & 45.9 & 21.7 & 26.5 & 1.1 & 4.8 & 100 & 172,935 \\
\hline Total & 46.2 & 23.6 & 24.6 & 2.5 & 3.2 & 100 & 1 '327,599 \\
\hline
\end{tabular}

Fuente: Elaboración propia basada en datos estadísticos migratorios de México. Instituto Nacional de Migración.

La transmigración centroamericana hacia eu tiene una larga historia. Viajar a través de México, también. Hubo un tiempo, no muy lejano (hasta antes de los años 80), en que los gobiernos de eu y de México prestaron poca atención a esa migración. Había razones para ello. Para eu no era un problema dado el bajo número de centroamericanos que ingresaban a su territorio. Después, cuando empezó a crecer el flujo, se toleró su presencia dados los conflictos político-militares que asolaban a los principales países exportadores de migrantes del Istmo y el interés en no dificultar más la labor a los débiles gobiernos centroamericanos de la época, que por lo demás hacían frente común con eu en lo que se consideraba parte de la conflagración mundial Este-Oeste. Con los acuerdos de pacificación en la región, en los

ricanos en México», bajo la responsabilidad del autor de este texto. Aquí se presentan algunos hallazgos del trabajo realizado en los términos en que se observaron en campo durante el periodo antes señalado y fueron analizados a la luz del proceso transmigratorio que ocurre en el país. 
años 80 del siglo xx el escenario empezó a cambiar. En Estados Unidos, desde mediados de ese decenio, se empezaron a introducir más requisitos para el otorgamiento de visas y nuevos controles fronterizos, en particular en su frontera sur. Durante los 90, y ya con la caída del Muro de Berlín, en esa frontera se verá cómo, de manera creciente, se irán estableciendo más dispositivos de seguridad y control que combinaban impedimentos físicos (bardas en lugares estratégicos), ${ }^{3}$ subjetivos (más personal para la Border Patrol, hoy parte del Departamento de Seguridad Interna, DHS por sus siglas en inglés), equipo y tecnología sofisticados. Los nuevos tiempos marcaron otras prioridades y se dio inicio a una serie de programas de control fronterizo que no acaban de concluir al día de hoy. ${ }^{4}$

Para México la situación es diferente, con sus bemoles. Por sí misma, la transmigración centroamericana nunca ha sido, ni es, problema para México. No lo es desde el momento en que los transmigrantes compran bienes (alimentos y medicinas, por ejemplo) y contratan servicios (transporte, hospedaje, etc.) dinamizando las actividades comerciales en las distintas localidades por las que transitan, con tiempos de estadía lo más breves posibles. Empero, la transmigración empezó a tener una dimensión de problema cuando eu modificó su política migratoria hacia Centroamérica. Por un lado se inició un nuevo ciclo de deportaciones estadounidenses hacia el sur (que afecta más y directamente, por el volumen de personas involucradas, a México) y, por otro, demandó a la parte mexicana mayor control de su bordo sureño. Es así como también en los 90 México instauró una nueva política inmigratoria y transmigratoria que pretende controlar los flujos con dirección sur-norte. México llegó a fin de siglo xx con una parte importante de su estructura administrativa y personal de migración orientado a procurar contener la transmigración centroamericana, y toda aquella indocumentada que viniera por la frontera sur mexicana, lo más cerca posible de esa frontera. La creación del Insti-

\footnotetext{
${ }^{3}$ Estados Unidos inició en los 90 una nueva estrategia de contención, la cual se prolongaría a lo largo de ese decenio con las siguientes medidas: 1991 y 1993 se levanta una cerca en California, por el rumbo colindante con la ciudad de Tijuana; en 1993 se aplican las operaciones Blockade y Hold the Line; en 1994 se aplica la Operación Gatekeeper; en 1995 la Operación Safeguard; en 1996 aprueba la ley migratoria vigente, conocida como IIRIRA por sus siglas en inglés, y en 1997 la Operación Río Grande.

${ }^{4}$ Los ataques del 11 de septiembre propiciaron que el gobierno estadounidense aplicara una nueva ingeniería institucional que pretende mejorar las capacidades de seguridad interna (180 mil funcionarios de 22 agencias, DHS), así como impulsar y aplicar un nuevo marco legal que incluye las siguientes medidas: Acta Patriótica, 2001, que triplica personal de inspección migratoria, aduanas y patrulla fronteriza en la frontera con México, incrementa el presupuesto para equipamiento tecnológico y refuerza regulaciones para impedir acceso de posibles terroristas; Acta sobre Ampliación de la Seguridad y Reforma de las Visas de entrada, 2002 (eBSVERA); Programa Nacional de Seguridad Nacional de Registro de Entrada y Salida, 2002 (NSEERS); Programa Us-Visit, 2003 (Visitor \& Inmigrant Status indicator Technology); SEvis, 2003 (Student \& Exchange Visitor Information System); Alianza para la Seguridad y la Prosperidad de América del Norte, marzo, 2005 (ASPAN), de Canadá, eu y México; Programa bilateral México-eu para la Persecución de Traficantes de Migrantes (Programa OASSIS), agosto, 2005; Iniciativa de Fronteras Seguras, EU, noviembre, 2005, nuevo nivel de prioridad en el combate a la migración indocumentada; y The National Security Strategy of the USA, marzo de 2006.
} 
tuto Nacional de Migración en los años primeros de los 90 es el hecho material y simbólico de esa nueva era de la política migratoria mexicana de la cual aquí se analizan algunos de sus rasgos centrales.

Frente al embate de los estados, la transmigración centroamericana por México reaccionó: fue estableciendo rutas y dinámicas de lo más diverso, primero con cierta holgura, después con más y más apremios y últimamente con riesgos mayores y crecientes. Pero siguen pasando. Frente a la acumulación de obstáculos jurídicos y administrativos para la obtención de visas se abrieron diversas ventanas y resquicios espaciales y se generaron rápidamente procesos sociales, humanitarios y de traficantes, que apoyaran, encauzaran y lucraran, según fuera el caso, con los flujos indocumentados internacionales. Sólo así se explica la existencia, en las grandes rutas migratorias, la multiplicación de agentes hoy existentes, producto de ese largo proceso migratorio y de las vallas legales que han tratado de contenerlo.

La creatividad de los migrantes y las redes sociales involucradas en los espacios de origen, tránsito y destino, no radicó, ni radica, de manera exclusiva en el señalamiento de un destino, por impreciso que éste sea en el Norte de América ("voy a California», sin saber en qué localidad californiana se encuentra su familiar o contacto), sino también en las formas específicas para migrar y en las adecuaciones que sobre la marcha hay que hacer a efecto de lograr la meta pretendida. Migrar de manera indocumentada es un desafío constante a la creatividad, propia de quienes hacen de ella un recurso diario de existencia. Una expresión de esa creatividad es la diversidad de rutas y la manera como éstas son utilizadas incluso en un mismo día por un grupo de migrantes diferente. Siendo principalmente las mismas, son diferentes las maneras como son concatenadas por cada oleada de migrantes. Así, de manera genérica puede decirse que las rutas son marítimas, aéreas y terrestres. Estas últimas, a su vez, se subdividen en: ferroviarias; de pie; de autobús de pasajeros; de autobús de carga; y de autos particulares. ${ }^{5}$ La mayor diversificación de puntos de ingreso y tránsito, en consecuencia, responde a distintas estrategias y momentos de transmigración. ${ }^{6}$

Los flujos centroamericanos, en particular, ingresan a México principalmente por un sinnúmero de caminos vecinales localizados en los estados de Chiapas y Tabasco. En los puntos que corresponden a la frontera norte de México, aún se observa el peso predominante de las rutas cercanas a las costas del Atlántico y Golfo de México, aunque ya empiezan a destacar las que se alejan de los territo-

\footnotetext{
${ }^{5}$ Las adecuaciones en rutas y medios que se generaron a raíz de los desastres climatológicos citados, dieron particular impulso al uso de vehículos de transporte público y particulares, según constatación en campo.

${ }^{6}$ Para una visión gráfica (incluye 16 mapas) del proceso transmigratorio por México, se recomienda la consulta de Una vida discreta, fugaz y anónima. Los centroamericanos transmigrantes en México, del autor de este artículo, publicado en 2007 por la Comisión Nacional de los Derechos Humanos de México y por la Organización Internacional para las Migraciones.
} 
rios de California y Texas, producto de las políticas de control fronterizo en EU. Hay efectos innegables de la habilitación de los nuevos lugares de detención y de los operativos de contención sobre el fluctuar de la oleada migratoria; por un lado, los registros agregados que antes se hacían para algunas delegaciones del norte del país, y que daban la impresión (equívoca) de que era en esos lugares donde se detenían a los indocumentados, ahora se presentan en correspondencia con los sitios administrativos en los que realmente ocurren las detenciones $y$, por otra, ahora es posible ver las implicaciones inmediatas de ese proceder gubernamental sobre los flujos transmigrantes y las respuestas de éstos una vez que han aprendido de las innovaciones gubernamentales generando a su vez nuevas formas de evadirlas, de ahí que hable del fluctuar del movimiento migratorio.

Fue en el decenio del siglo xx cuando se impulsó la construcción o habilitación de locales denominados estaciones migratorias, espacios dedicados de manera exclusiva para la reclusión de extranjeros indocumentados en espera de su devolución al país de procedencia. Para el año 2000 había una Estación Migratoria en el Distrito Federal y 24 estancias migratorias (una en Chihuahua, una en Sinaloa, dos en Tamaulipas y las 20 restantes en Guerrero, Oaxaca, Tabasco, Chiapas y Veracruz). El número mayor de estaciones en el sur-sureste denotaba, desde ese entonces, la intención de contener la transmigración indocumentada en la zona limítrofe con Guatemala, principalmente, y Belice, que ha presentado un volumen menor de migrantes internacionales. Para 2005 ya había 52 estaciones migratorias (con cambios en la nomenclatura, clasificación de los locales, recursos materiales y técnicos, personal, entre otros), la mayoría ubicadas en los estados del sur-sureste, destacando el estado de Chiapas con 15,7 bajo el mismo esquema general de contención de la transmigración. Dicho de otra forma, se mantiene constante la intención de contener la transmigración indocumentada y las medidas que se observan responden a un fortalecimiento de dicho propósito, con eventuales mejoras en los sistemas de registro, detención, conducción y devolución de los indocumentados. Hay cambios en los procedimientos pero no en la concepción de política migratoria mexicana. Para 2007 se redujo el número de 52 a 48 estaciones migratorias, debido principalmente a que los locales no cubrían los requisitos mínimos para su cabal funcionamiento y eran motivo de crítica pública y de observaciones por parte de la Comisión Nacional de Derechos Humanos. ${ }^{8}$ Su distribución a lo largo del territorio nacional muestra una innegable intención de contención de los transmigran-

\footnotetext{
7 Las estaciones migratorias se ubican en El Manguito, Huehuetán, Hueyate, Echegaray, Ciudad Cuauhtémoc, Playas de Catazajá, Mazapa de Madero, Talismán, Frontera Corozal, San Gregorio Chamic, Tuxtla Gutiérrez, Comitán, Palenque, San Cristóbal de las Casas y Tapachula.

${ }^{8}$ Ver, por ejemplo, el Informe Especial de la Comisión Nacional de los Derechos Humanos sobre la «Situación de los Derechos Humanos en las Estaciones Migratorias y Lugares Habilitados del Instituto Nacional de Migración en la República Mexicana» del 01/09/06. Por distintas razones, las 48 estaciones existentes siguen siendo objeto de crítica fundada, sin que se logren cambios cualitativos sustantivos que mejoren las condiciones de reclusión, de acceso o procesos que en ellas se efectúan.
} 
tes indocumentados. Las estaciones migratorias están situadas principalmente en las ciudades que conectan vías torales de transporte terrestre y en puntos estratégicos de internación marítima y aérea del sur y centro del país, así como en importantes ciudades del norte o pasos fronterizos hacia Estados Unidos, lo que constituye una especie de frontera migratoria vertical a lo largo del país, con sus ramificaciones a las vías de comunicación cercanas a las costas nacionales. ${ }^{9}$

Pese a las medidas tomadas, el flujo transmigratorio no fue contenido, aunque no se pueda precisar su grosor. Lo que ocurrió fue una diversificación de los lugares de aseguramiento y no necesariamente una contención significativa no obstante que hubo un incremento en el total nacional de eventos de aseguramiento hasta 2005 $(240,269)$; la caída posterior en el total de aseguramientos para $2006(182,705)$ y 2007 (43,780 a septiembre) responde más a una posible baja transitoria del flujo debido a los ya mencionados desastres climáticos de finales de 2005 y años sucesivos (algunos de ellos también afectaron a los países centroamericanos), que también dificultaron la labor de las autoridades migratorias, a la modificación consecuente de las rutas migratorias, a la rápida adecuación de las redes de traficantes y generación de nuevas que vieron, con los desastres, una oportunidad de ampliar su oferta de servicios, con el inmediato incremento de costos, etc., pero no debido a una acción efectiva de la autoridad migratoria. ${ }^{10}$

\section{DISTINCIONES FUNCIONALES DE LAS RUTAS}

La conjugación de medidas administrativas de contención y detención, desastres naturales, dinamismo de las redes de traficantes y los altibajos en el espectro social de asistencia motivó a los transmigrantes a buscar nuevas vías de acceso al Norte. Se pueden hacer distinciones funcionales de las vías de traslado conforme a su utilización. Las rutas pueden ser principales y secundarias, según el criterio que

\footnotetext{
${ }^{9} \mathrm{Al}$ momento de hacer correcciones finales este artículo (junio de 2008), se sabe de manera extraoficial que habrá modificaciones sustantivas en la actuación del INM en la frontera sur mexicana, que incluyen la construcción de más (cinco o seis) estaciones migratorias y la eventual remodelación de algunas de las existentes. Las autoridades migratorias de México tienen, adicionalmente, altas expectativas de recibir recursos importantes extraordinarios por la Iniciativa Mérida, bajo el supuesto de que serán destinados al combate del tráfico de personas; al momento de revisar el texto no se ha difundido los rubros y montos de dicha Iniciativa por lo que no es posible emitir opinión con mayor detalle.

${ }^{10} 2005$ fue año de efervescencia político electoral en el que ocurrieron varios cambios a nivel de titulares de la Subsecretaría de Población, Migración y Asuntos Religiosos, del INM, y en instancias subordinadas de éste como en la Coordinación de Delegaciones y de Delegado Regional en los estados de Chiapas y Veracruz, entre otros, de suerte tal que con tantos cambios en puestos de mando difícilmente se podrían haber aplicado medidas exitosas y de cierta continuidad, cuando reinaba la incertidumbre laboral entre el personal medio y de base del área migratoria gubernamental. En 2006, con el inicio de una nueva administración federal, vinieron cambios en la Secretaría de Gobernación y en las dependencias ya citadas, lo que tampoco ayudó a la generación de nuevas políticas exitosas, sino a la instalación y aprendizaje de nuevos mandos en la materia.
} 
se siga: ruta larga o corta; ruta segura; ruta económica; ruta alternativa; y combinación de ellas. Según las circunstancias, una ruta puede tener un tramo principal, no toda ella lo puede ser. Depende de qué obstáculos represente para el transmigrante que lleve a éste a ser selectivo en su uso. También puede ocurrir que en un momento dado una ruta pueda ser principal y en otro secundaria. Nuevamente, depende de qué nuevo ocurra en ella; nuevos controles migratorios, presencia de redes delictivas, hallazgo de otra ruta más conveniente, etc. Es decir, ser principal o secundaria es una connotación totalmente relacionada con diversos elementos que los migrantes y las redes de apoyo o de traficantes van conociendo y compartiendo con las oleadas de migrantes que les siguen.

Las rutas son autónomas cuando sólo sirven para propósitos del flujo migratorio y son compartidas cuando se usan para otros propósitos (narcotráfico, por ejemplo). Esto es, la naturaleza de las vías de comunicación (carreteras y vías férreas) existe para los propósitos públicos que las originaron. La diferencia es que quienes están en la lógica de la transmigración les otorgan una segunda naturaleza acorde al fin que pretenden. De ahí que unos opten, de acuerdo con su concepción particular del riesgo, por las más transitadas y otros por las menos. Unos piensan que en la masa social encuentran la porosidad que facilita su transitar. Otros, por el contrario, piensan que en el campo despoblado es más fácil detectar y evadir el control migratorio o autoridad gubernamental de paso dado que el brazo de la autoridad apenas alcanza para cubrir arterias principales y (muy) ocasionalmente las secundarias. Así, habrá quienes consideren una ruta como principal y otros como secundaria, al mismo tiempo. Pero a la vez, habría quienes las consideren autónomas, no tanto porque lo sean, sino porque desconocen la actividad de otras redes que las usan para traficar personas, bienes u objetos sin su conocimiento. Esta diferenciación sirve para entender el que unos flujos vayan por una vía, se desvíen y tomen otra, para más adelante regresar a la primera. La sinuosidad de los flujos responde más a la lógica de sus percepciones que a las ondulaciones de la red de carreteras oferroviaria que utilicen.

Los transmigrantes no construyen caminos, hacen suyos los que ya existen. No requieren de permiso para servirse de ellos. Practican el libre tránsito, aunque para ello tengan que pagar derecho de paso a delincuentes y oficiales abusivos. Así lo han hecho desde tiempos idos. Los controles migratorios son obstáculos, no necesariamente impedimentos. Cuando alguna autoridad les pide su pase migratorio buscan la manera de evadirla, o de obtener (o adquirir, con frecuencia a petición de parte) la buena voluntad del agente público para que les franquee el paso. Pocas veces, muy pocas y muy pocos, recurren a la violencia para seguir desplazándose. Como dijera un transmigrante salvadoreño: le tienen más miedo al hambre que a la muerte, por eso no los detienen. Y, si lo hacen, reinciden. Si los alcanza la muerte, mueren sólo ellos. En cambio el hambre asola a toda la familia. Por eso, dice, es más de temer la hambruna «que la huesuda». A migrar al Norte lo han aprendido 
desde niños y al paso de generaciones. Sortear los avatares de viaje lo han aprendido escuchando en casa las experiencias de generaciones previas o de las contemporáneas que se les han adelantado, con las vivencias de casa y con la experiencia propia al emigrar. Emigrar es una manera de sortear el hambre, es una manera de ser.

Las rutas terrestres son las más utilizadas y, entre ellas, la ferroviaria es la más socorrida en últimas fechas. El tren de carga es, por excelencia, el medio ferroviario de los transmigrantes. Quienes más recurren a él son, mayoritariamente, la masa de transmigrantes con menos recursos pero no totalmente carentes de ellos pues, aunque viajan de polizontes, tiene que hacer pagos indebidos a funcionarios que medran con los indocumentados, o bien a guardias de seguridad privada y personal asalariado del tren, sea para dejarlos subir, no bajarlos, o bajarlos antes de un retén, o no disminuir la marcha ante un control migratorio, etc. Es decir, el viaje tiene un costo económico, a veces corporal para los centroamericanos transmigrantes (con mayor frecuencia para las mujeres).

Las rutas terrestres de transmigrantes centroamericanos en México se caracterizan por ser muy estrechas en la porción sureste, sobre todo debido a la forma que presenta el territorio mexicano. Conforme se acerca a la porción central, dichas rutas tienden a diversificarse. Ello obedece principalmente a la conformación de infraestructura carretera y de transporte férreo. Es importante destacar que la población transmigrante se vale de los medios existentes para transitar a lo largo del país durante su travesía a los Estados Unidos. Es decir, no tiene necesidad de trazar nuevas rutas o vías de comunicación alternativas a las existentes.

El acercamiento a la región sureste del país permite observar las rutas de internación, los corredores principales y secundarios. Ciertamente, estas vías se alimentan, particularmente en los estados de Chiapas y Tabasco, de un sinnúmero de caminos vecinales que les acercan a la ciudad de Tapachula, Palenque, Arriaga y Tenosique, principalmente. Algunos sitios por las inmediaciones fronterizas de Tabasco son de muy difícil control y de alto riesgo en general por ser rutas utilizadas para el narcotráfico; las inundaciones de las carreteras afectan a todos los que las usan y se sirven de ellas y, en consecuencia, las pocas vías disponibles se vuelven más competidas en detrimento de quienes menos protección tienen, es decir, los indocumentados. Hay otras vías públicas que se entremezclan entre Chiapas y Tabasco que tienen más relación con el centro del país y hacen más expedita la travesía indocumentada. Circunstancialmente, debido a la desaparición de la estación ferroviaria de Tapachula en 2005, los transmigrantes han tenido que ir más al noroccidente chiapaneco, hasta Arriaga, travesía que les toma casi una semana de caminata, lo que les expone a las redes delictivas que se han instalado entre Pijijiapan y Arriaga. Para evitar ese riesgo, más que adentrarse en territorio chiapaneco, hay quienes prefieren orientarse hacia Tabasco vía Palenque o directamente por Tenosique, lo que tampoco es garantía de inmunidad, sino de menor riesgo relativo, según consideran algunos. 
Hay sitios considerados como plataformas, otros son puertos de enlace y otros más sitios de paso. En particular, los aeropuertos siguen una lógica diferente dados los mayores controles que ocurren en ellos, que dificulta el uso masivo y encarece su eventual utilización:

- Plataformas: zonas de concentración donde arriban, reagrupan, resguardan y parten los grupos de migrantes;

- Puertos de enlace o nodos: lugares provistos de rutas alternas desde donde se redireccionan los migrantes; y

- Sitios de paso: lugares en los que se pasa y no se detiene el migrante, o hace una escala breve.

En los lugares de tránsito los transmigrantes encuentran:

1. Casas solidarias con individuos y redes sociales que les proveen de información, asistencia alimentaria, hospedaje, servicios de salud, limpieza, jurídicos, etc. En determinados momentos algunos albergues humanitarios son utilizados por redes de traficantes que les meten a trasmano «sus pollos» o buscan enganchar a otros dentro de las casas. Por otra parte, esas casas son con frecuencia infiltradas por distintos agentes de los cuerpos de seguridad municipal, estatal o federal. Esas acciones ocurren a contra pelo de la voluntad y vigilancia de los responsables de los mismos, que aparte de esforzarse genuinamente en su labor humanitaria tienen que vivir el estrés del hostigamiento; 11

2. Casas de seguridad (para las redes delictivas), de difícil ubicación para el analista social y de previsibles consecuencias a su seguridad personal si, sabiendo de ellas, las señala. Hay indicios de que algunos hoteles llegan a ser utilizados para tal efecto, tanto en el sur-sureste como en localidades del centro-norte y en localidades fronterizas del norte mexicano, aparte de casas que igualmente se encuentran en lugares estratégicos de las rutas principales de transmigración; y

3. Espacios públicos: plazas, mercados, centrales de autobuses, estaciones y patios de redes ferroviarias, etc. Estos espacios, por lo regular, son los privilegiados por quienes menos apoyos y recursos tienen. A la vez, esos espacios son igualmente utilizados por traficantes, sean para «disfrazar» sus grupos, para enganchar migrantes, para buscar y encontrar posibles coadyuvantes para el trasiego de mercancía ilícita, sea para darles un descanso a sus grupos, o para deshacerse de ellos.

\footnotetext{
${ }^{11}$ En las rutas se han localizado diferentes organismos que dan atención directa a los migrantes centroamericanos. Según el padrón que integra una red de asociaciones civiles, centros de derechos humanos, albergues y casas vinculadas a la migración en México (el Foro Migraciones), no todos los organismos dan atención directa a los transmigrantes centroamericanos, sólo algunos de ellos lo hacen, otros han desaparecido, como ocurrió en Veracruz, o están en proceso de conformación; otros más brindan algún tipo de ayuda humanitaria pero no ponen atención especial en las violaciones a los derechos, ni su registro. Ver Directorio del Foro Migraciones, 2006, México, mímeo.
} 
Este mapa permite identificar las principales rutas por las cuales se desplazan los transmigrantes por las vías terrestre, marítima y aérea. ${ }^{12}$ Existen dos rutas terrestres principalmente. La ruta del Golfo es la más corta y presenta mayor tránsito, su flujo incluye a la población centroamericana y también a la que procede del Caribe. La ruta del Pacífico es más extensa. Sin embargo su empleo sirve principalmente a la población que tiene como destino el occidente de Estados Unidos, California principalmente. Los puntos de internación aérea son menos transitados debido al elevado costo (pasajes y corrupción) que ésta implica, así que son utilizados especialmente por los transmigrantes con mayores posibilidades económicas (indocumentados transcontinentales, asiáticos en particular que no tengan que hacer escalas laborales en México) y que emplean las ciudades marcadas como puntos de internación aérea en tanto enlace con otros medios de transporte.

\section{MAPA}

Principales rutas de los centroamericanos transmigrantes y otras nacionalidades en México, 2001-2005

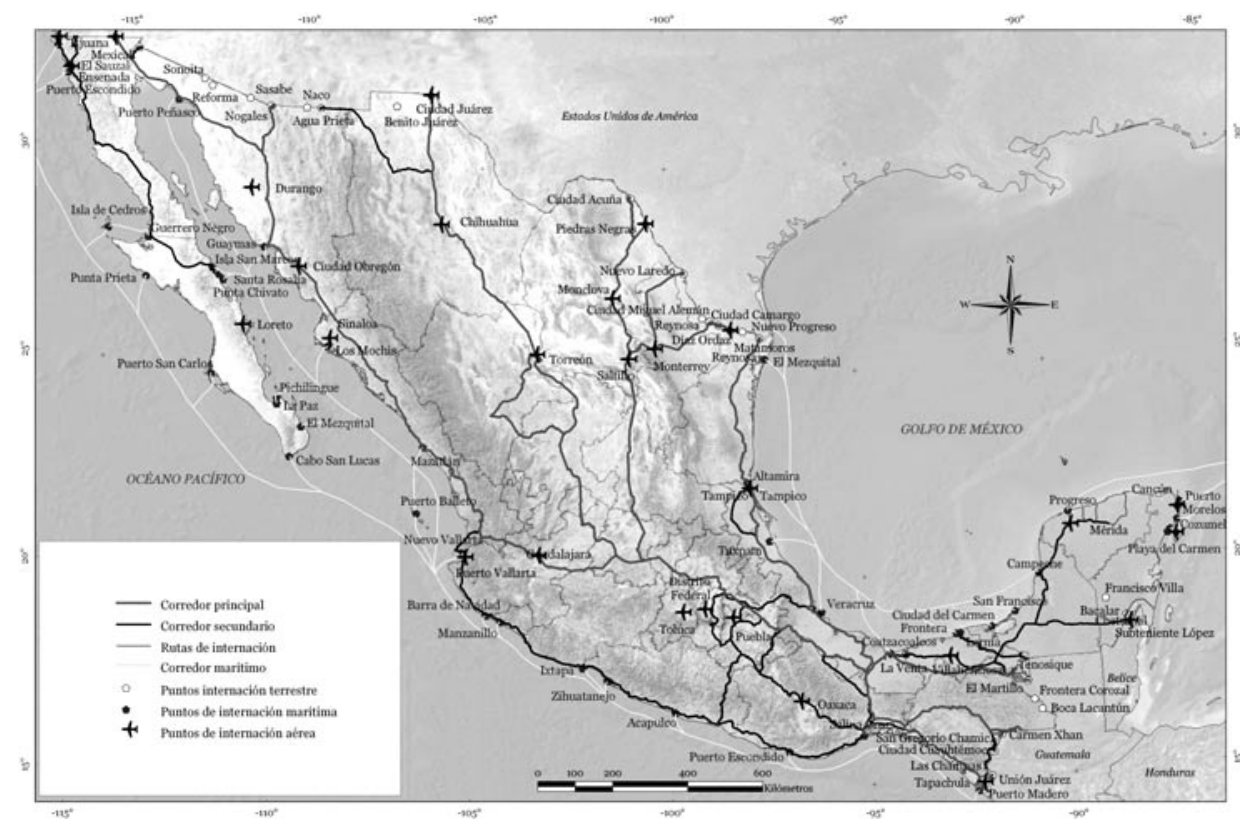

Base cartográfica: INEGI. Carta topográfica 1: 1,000,000. conabio. México imagen desde el espacio. Mosaico 2002 de imágenes Modis sin nubes del satélite Terra, sobre un modelo digital de terreno. Proyecto: Presente y Futuro de los centroamericanos transmigrantes en México.

Responsable del proyecto: Rodolfo Casillas R. Autores: Leticia Gerónimo Mendoza y Rodolfo Casillas R.
Datos de la proyección. Proyección: Cónica Conforme de Lambert Falso Este: 2,500,000

Falso Norte: o

Meridiano Central: -102

Latitud de Origen: 12

Paralelo Standar 1: 17.5

Paralelo Standar 2: 19.5

Datum: NAD 1927

Esteroide: Clarke: 1866

${ }^{12}$ Para efectos de la ilustración de las rutas marítimas se han trazado líneas alejadas de las costas, pero el traslado real ocurre pegado a ellas lo más posible; por un lado las pequeñas embarcaciones 
Los migrantes indocumentados son, en general, objeto de asaltos, abusos y violaciones de sus derechos humanos. En particular, los transmigrantes, mujeres, adolescentes, niñas y niños son quienes enfrentan mayores riesgos de abuso y violación (hay casos de mujeres que han sido violadas más de 20 veces, y aún no llegan a la frontera norte de México; es decir, existe la posibilidad de que en el trayecto faltante puedan ser objeto de más agresiones similares). Aunque las violaciones pueden ocurrir en cualquier lugar del país, hay algunos sitios con mayor recurrencia del delito o que destacan en fecha reciente como tales. ${ }^{13}$ Ello se debe, entre otras razones, a las acciones y programas de las autoridades migratorias que tratan de contener los flujos de transmigrantes, los que a su vez modifican las rutas de traslado y la reubicación geográfica consecuente de los victimarios. Así, surgen nuevos sitios que desplazan a otros en su importancia estratégica. Al empujar los flujos de las costas hacia el centro, lugares como San Luís Potosí se convierten en espacios que reúnen migrantes $y$, rápidamente, a traficantes de personas extranjeras. Existen evidencias empíricas sobre el creciente número de violaciones de los derechos humanos de dichos migrantes durante su estadía o paso por México. Pero es práctica común que las víctimas no acudan a las instancias estatales competentes a presentar la denuncia correspondiente. Parte de la escasa información sobre las violaciones llega a oídos de miembros de organismos humanitarios que asisten a los migrantes, y sólo unos cuantos de esos organismos civiles registran las violaciones. Por otra parte, cada uno de estos organismos elabora sus propias bases de datos, por lo que no existe una base común, complementaria, con una metodología afín, entre otros aspectos técnicos y sustantivos. De esta suerte no existe un registro nacional sobre el número de violaciones de los derechos humanos de los migrantes, ni materia prima suficiente para la caracterización de dichas violaciones, periodicidad, agentes que las comenten y circunstancias sociales y territoriales en que ellas ocurren. ${ }^{14}$

Transmigrar cuesta. Hay una relación directa entre mayores obstáculos para migrar y mayores costos de traslado. Las políticas migratorias de los estados del norte del continente han estimulado dos efectos secundarios negativos; el aumento de redes de traficantes y el encarecimiento del traslado migratorio. La combina-

evitan el riesgo de navegar por alta mar y, por otro, pueden hacer un rápido desembarco en caso de ser necesario.

${ }^{13}$ El Informe del Albergue Belén 2008, que comprende el 1 de mayo de 2007 al 15 de febrero de 2008, presenta un listado de 15 entidades federativas en los que ocurren dichas violaciones. Si se toma en cuenta, como referencia lo presentado por el mismo albergue para los años anteriores, se concluye que cada vez más aumenta el número de sitios en que se cometen dichas violaciones de manera impune.

${ }^{14}$ Un caso digno de mencionar es el esfuerzo continuado desde hace años en el Albergue Belén de la ciudad de Saltillo, con una metodología que se mantiene en lo principal y que ha dado ya informes significativos en los años 2006 y 2007 bajo la responsabilidad de Frontera con Justicia, A.C. 
ción de ambos efectos desangra más la economía de los transmigrantes que se ven obligados a recurrir a distintos mecanismos de financiamiento durante el trayecto en México: 1) Ahorro inicial (o empréstito, venta de bienes o envío de recursos desde eu); 2) Trabajo temporal (en particular, en el caso de las mujeres, éste incluye el sexual en un mayor porcentaje y recurrencia que en el caso de los hombres); 3) Envíos electrónicos escalonados; 4) Asistencia humanitaria. Es decir, acudir a los albergues humanitarios que encuentran a lo largo de su travesía por México; y 5) Aventones. En particular a los transportes de carga en lugares estratégicos de México, como las centrales de abasto de alimentos.

Las rutas migratorias pueden ser continuas o permanentes. Ello depende de: 1) La realización de operativos del INM (volantas), lo que ocurre más en los estados de Chiapas, Oaxaca, Tabasco y Veracruz, en lugares estratégicos, sea porque hay cruces o bifurcaciones de carreteras, estaciones de tren, etc; 2) La instalación de puestos fijos del INM u otra autoridad que realice controles para efectos diversos; 3) Cambios en el personal del INM $u$ autoridades en controles que implique renegociación de protección; 4) Creación de nuevas redes de apoyo o de tráfico comercial; 5) Ocupación con tintes de exclusividad de las existentes por redes de tráfico ilícito, como ocurre en algunos tramos de acceso de Guatemala con la región fronteriza en que convergen los extremos de Tabasco y Chiapas; 6) Construcción de nuevas vías de comunicación pública, como ocurrió en algunas partes de Chiapas luego del inicio del movimiento zapatista de 1994; 7) Desastres naturales como los ocurridos a finales de 2005 y en 2006 con los huracanes que afectaron en particular a localidades chiapanecas y la red ferroviaria que partía de Tapachula; y 8) Obstáculos previsibles en la frontera sur de Eu como nuevas disposiciones migratorias en el área limítrofe, la presencia de la Guardia Nacional, los grupos antiinmigrantes, etc.

El mapa aquí presentado sintetiza el total de rutas aéreas, marítimas y terrestres utilizadas por los centroamericanos transmigrantes y provenientes de otros países (principalmente Cuba y el continente asiático). En todos los casos señalados de las distintas rutas no se indica su concatenación, sino su utilización; aquélla ocurre según la manera como se conjugan distintos elementos de juicio del momento de que disponen los transmigrantes y quienes les asisten, o conducen, en el trayecto.

Los crecientes flujos de migrantes internacionales a México y de paso por él, sobre todo los indocumentados que provienen del sur continental, no podrían explicarse cabalmente sin el concurso de distintas redes de traficantes de migrantes que, desde su lugar de origen o residencia, a lo largo de su trayecto y en el lugar de destino participan de manera activa en facilitar el desplazamiento poblacional. Debido al desconocimiento de cómo se organizan y funcionan esas redes se ha sobredimensionado la figura del pollero o coyote, que en muchos casos es presentado cómo el único agente o traficante de migrantes. El pollero es, en muchos casos, 
un agente (público o privado) que se subarrienda a diversos organismos y que puede o no hacer del tráfico su actividad principal, lo que no niega la existencia de polleros independientes que concentran en sí mismos la diversidad de funciones por realizar; son éstos los que con mayor frecuencia caen en manos de las autoridades públicas, justamente por su actuación individual o escasamente articulada. En algunos casos, polleros y «pollos» caen en manos de las autoridades por delación de otros traficantes. Es probable que el menor número de detenciones de polleros que realizan las autoridades sea producto de su propio trabajo.

En las redes de traficantes de migrantes existe una estratificación de funciones. ${ }^{15}$ Algunas de ellas son necesariamente visibles, mientras que otras requieren permanecer en la opacidad para el cabal cumplimiento de sus funciones. Existe una diversidad de funciones que van desde reclutar, organizar, cuidar, escoltar, guiar y cobrar que recaen en diversos operadores, pues el tráfico de personas es un proceso en el cual cada persona que participa tiene funciones delimitadas, sean parte o no de una estructura formal. Entre las mismas redes delictivas ocurren diversos niveles de competencia entre todos los recursos humanos y materiales que una organización posee a base de contactos en el desarrollo de sus operaciones. Es ahí donde muchos de los agentes (públicos y privados) tienden a subarrendar sus servicios con otros, con redes que se han ido entretejiendo. El éxito de la actuación de las organizaciones de traficantes se basa en su red de colaboraciones por el simple hecho de que, en caso de que alguno de sus agentes visibles sea sorprendido y capturado por la autoridad, lo más que pierde es un elemento físico, uno de tantos intermediarios de su compleja estructura, de fácil sustitución, dejando la red delictiva a salvo.

Entre los elementos que integran la red de tráfico se encuentran desde particulares ligados al sector de bienes y servicios, agentes privados (como son familias) con arraigo en localidades ajenas al tráfico, jóvenes, trabajadores del campo y agentes públicos (entre los que destacan policías municipales y agentes de migración, sobre todo los que laboran a nivel local). Esta amplia y diversa participación multisectorial es lo que permite hablar de una estructuración de colaboraciones de diverso tipo y, tomando en cuenta la antigüedad de la migración, es posible señalar la reproducción social de ya considerable data de este conjunto de prácticas delictivas, en las que muchos de los participantes se conocen por estar, por haber estado, por iniciarse o hacer sus primeras incursiones en el tráfico de personas. Esta corrosión delictiva invade a instituciones de los distintos niveles de gobierno y diversa ubicación en las escalas de mando y operación, así como a diversos segmentos sociales desde hace tiempo, de manera ininterrumpida e impune hasta ahora.

Los países centroamericanos, al igual que México, reciben cada año montos crecientes de envíos monetarios, o remesas. Las remesas, como los flujos, con frecuencia son relacionando lugar de origen y destino. Una atención menor se ha dado,

\footnotetext{
${ }^{15}$ Aquí sólo se hace referencia a las que desarrollan sus labores en espacios abiertos del sur-sureste mexicano, lo que no implica desconocer la existencia de otro tipo de redes que delinquen en espacios cerrados, institucionales, con atención prioritaria a migrantes documentados.
} 
hasta el momento, al espacio de tránsito, tanto de los flujos como de los envíos escalonados que facilitan la movilidad internacional. En esa lógica (origen y destino del envío) se pueden ubicar los señalamientos del cuadro siguiente.

CUADRO 3

Montos de remesas por país*

\begin{tabular}{|c|c|c|c|}
\hline PÁ́S/AÑO & 2000 & 2005 & 2006 \\
\hline Guatemala & 563 & 2,993 & 3,610 \\
\hline El Salvador & 1,751 & 2,830 & 3,320 \\
\hline Honduras & 410 & 1,788 & 2,300 \\
\hline
\end{tabular}

* Cifras en millones de dólares de Eu.

Fuente: Elaboración propia con datos de The World Bank Migration and Remittances Factbook http:// go.worldbank.org/OOWEWD6TA0 y Inter-American Development Bank. 2008. «El Salvador and Remittances.» January 10. On-line report: http://www.iadb.org/mif/remittances/lac/remesas_es.cfm

En la medida en que se facilita el acceso al servicio de envío electrónico, disminuyen los costos de la transacción, se diversifica territorialmente la red de servicios financieros en los lugares de tránsito y destino, se cuenta con distintos oferentes de servicios y se incrementa el flujo de migrantes, las remesas tienden a incrementarse. Estos procesos institucionales y sociales han ocurrido en los últimos años. Las tendencias indican un mayor desarrollo y complejidad de la relación remesas-migración-sociedad. Si fuera posible analizar los registros de las empresas dedicadas al envío/cobro de remesas se podría profundizar en el análisis diferenciador de los montos que provienen de Estados Unidos para la transmigración y cuáles otros financian el retorno de quienes desisten de proseguir hacia el Norte, se podría saber nacionalidades, temporalidades, etc., pero ello no es posible dado que son registros privados. Queda, al menos, el consuelo de saber que dichos registros existen; habrá que buscar la oportunidad de acceder a ellos. Mientras, con la materia disponible se pueden presentar algunas de sus implicaciones diarias con el debido concurso de muy distintos actores y benefactores.

Una de las estrategias más efectivas utilizada por los transmigrantes en los últimos años es la recepción dosificada de remesas a lo largo de su paso por México, sea para continuar la travesía al Norte, sea para el retorno de quienes desisten de continuar. Esta práctica de envíos dosificados de remesas también genera nuevos mecanismos y formas de cohesión social entre transmigrantes centroamericanos en tierras mexicanas de tránsito y entre ellos y grupos sociales locales, aunque también ha dado lugar a secuestros Express, los que ya ocurren en cualquier momento y lugar de la travesía por México. Éstas son otras caras de las remesas centroamericanas con destino México escasamente conocidas y analizadas. Por un lado, pues habría que verlas a la luz de los procesos de articulación y cohesión entre migrantes, entre éstos y sus patrocinadores en EU, entre migrantes y entornos sociales por los que transitan, entre migrantes y núcleos familiares de procedencia y, a final de cuentas, entre migrantes y grupos sociales allende fronteras, 
tanto en lugares de procedencia, tránsito y destino. Es decir, un fortalecimiento del tejido social desde, por y para el mundo subalterno de los migrantes, con efectos que no se circunscriben a dicho mundo ni tampoco se limitan a los espacios territoriales nacionales de donde son oriundos los transmigrantes. Por otro lado, esas mismas remesas abren otro flanco de vulnerabilidad al migrante indocumentado como se argumenta en las siguientes líneas.

Los envíos escalonados funcionan con beneficios múltiples para actores sociales diferentes, con propósitos igualmente diferentes:

a) Para el emisor. Le permite el envío de montos menores en plazos determinados. Ya no es necesario un periodo mayor de tiempo para acumular el monto total de lo requerido para el traslado, antes de que éste se inicie, máxime que los costos económicos de traslado se han incrementado. ${ }^{16} \mathrm{~A}$ la vez, se anula el riesgo de pérdida total o mayor, circunstancia que prevalecía cuando no había la modalidad de los envíos electrónicos escalonados. Ciertamente prevalece el riesgo de la pérdida del envío dosificado. Pero éste, de ocurrir, es un costo menor y de relativa fácil absorción;

b) Para el receptor. Contar con la liquidez necesaria para cubrir una etapa determinada del trayecto es una doble garantía: puede cubrir la distancia o trayecto deseado y le da una garantía de vida. Esas erogaciones incluyen el «derecho de paso» que, de manera irregular de acuerdo con la ley pero regular debido a la práctica consuetudinaria, cobran agentes gubernamentales (corrupción) o actores sociales (asalto, robo, prestación de algún servicio, adquisición de alimentos, medicamentos u otro bien necesario). Hacer pagos indebidos le significan al migrante poder transitar con riesgos menores. Dado lo extendido de la práctica, cabe la presunción de que la mayor parte del total de las remesas para el traslado o paso por México se destinan a cubrir los «derechos de paso» exigidos de manera ilegal;

c) Para las redes delictivas. Contar con ingresos seguros, así sea una labor atomizada que les requiera más tiempo y esfuerzo, sin recurrir de manera necesaria a la violencia extrema ${ }^{17}$ les da un beneficio adicional: su acción delictiva, al atomizarse, obstaculiza que sea vista en su justa dimensión tanto por las autoridades públicas, por los organismos humanitarios y por los propios migrantes afectados. En consecuencia,

${ }^{16} \mathrm{~W}$. Cornelius estima que los precios que cobran los polleros se han triplicado desde 1993. Asevera que antes de la implementación de la Operación Guardián, un coyote o pollero cobraba en promedio \$143 dólares por cruzar a un migrante en la zona de San Diego/Tijuana. Para 1990 esta cifra había aumentado a $\$ 490$ dólares. Para el 2001 los polleros que operaban en la zona de San Diego y El Centro llegaron a cobrar entre $\$ 1,200$ y $\$ 1,500$ dólares por persona. Para enero del 2006 las tarifas oscilaban entre los $\$ 2,000$ y $\$ 3,000$ dólares. Las tarifas suelen ser más altas cuando la migración implica recorrer grandes distancias. Migrantes indocumentados provenientes de la provincia de Fujian, China, llegan a pagar entre 30 mil y 40 mil dólares por ser llevados a América del Norte, Europa, o Japón. Un estudio de la ort estima que el negocio de tráfico de personas genera anualmente entre 5 y 10 mil millones de dólares en ganancias en todo el mundo. Se recomienda la consulta de: Cornelius, Wayne, Thomas Espenshade e Idean Salehyan (eds), The International Migration of the Highly Skilled, Center for Comparative Immigration Studies, University of California, San Diego, 2001 y Cornelius, Wayne, Philip Martin and James Hollifield, Controlling Immigration. A Global Perspective, Stanford University Press, 1994.

${ }^{17}$ El secuestro Express de migrantes indocumentados es un ejemplo de violencia extrema. Esta modalidad delictiva se ha visto favorecida por el envío de remesas escalonadas, de suerte tal que este tipo de secuestros ocurre en localidades del sur de México (como Chiapas, Tabasco, Oaxaca) y no 
ese encubrimiento inhibe el conflicto social, desarticula la protesta activa de los afectados y no da lugar a la acción correctiva gubernamental, que por lo regular procede ante hechos de notoria espectacularidad;

d) Para las instancias gubernamentales. La existencia de un mecanismo ad-hoc que inhibe, distiende o pospone el conflicto social, así exista y opere sin control estatal, disminuye en el corto plazo la presión social sobre el Estado, en particular sobre las instancias del Ejecutivo con responsabilidad en materia social, migratoria, laboral y de justicia;

e) Para las organizaciones sociales humanitarias. Algunas, no todas, y bajo diferentes perspectivas y prácticas, facilitan un servicio asistencial que, sin proponérselo en muchos casos, constituye parte de una más amplia estrategia social de reproducción de la migración indocumentada; y

f) Para las empresas de servicios múltiples, bancarias y de bolsa. En tanto medios internacionales por los que se realiza el envío de remesas, incrementan su cartera trasnacional de clientes y servicios, es decir, aumentan su presencia y ganancias en un mercado internacional promisorio. Unos números para ilustrar: de los países presentados en el cuadro 3, el total de sus transacciones en el año 2000 fue de 2,724 millones de dólares y para el 2006 fue de 9, 230, es decir más que se triplicó el monto en seis años. Si sólo se toma en cuenta el costo de envío y el tipo de cambio utilizado, las ganancias para dichas empresas es impresionante. No obstante, el sistema diferenciado de envío de remesas a nivel internacional es muy complejo, con costos significativos para los países latinoamericanos. ${ }^{18}$

Este conjunto de prácticas, no coordinadas entre sí pero que ocurren de manera simultánea, y algunas se complementan, generan un valioso mecanismo de reproducción y cohesión sociales de los migrantes en su calidad de grupos subalternos de alta vulnerabilidad social en un espacio territorial ajeno, el interregno mexicano. La eficacia de este mecanismo, por otra parte, contribuye a explicar el crecimiento y diversificación de los flujos a pesar de las políticas migratorias altamente selectivas que les excluyen. Dicho de otra manera, las remesas a los migrantes en tránsito por México aportan un plus cohesionador intangible pero altamente eficaz al contrarrestar las acciones que les lesionan en su tránsito por México. Adicionalmente, las remesas atenúan el conflicto social, y lo convierte en tensión constante, en tanto sean efectivos y satisfactorios los efectos redistribuidores de las remesas para el traslado entre los distintos actores sociales involucrados. Es importante, por tanto, analizar la relación remesas para la transmigración (y el retorno)-transmigración centroamericana y valorar el papel que juega cada uno de los actores sociales identificados en dicha relación, pues hay participaciones y actores que hacen un uso abusivo del marco

sólo en localidades cercanas a la frontera mexicana con Estados Unidos, bajo la expectativa de que el monto del rescate puede ser enviado por vía electrónica a cualquier parte y cuenta que se les indique a los interesados en rescatar a la persona secuestrada.

${ }^{18}$ Se recomienda consultar la ponencia de Manuel Orozco «Remittances and Development: issues and policy opportunities», presentada en el Foro Global Migración y Desarrollo, celebrado en Bélgica en 2007. 
legal, mientras que otros potencian su labor delictiva al extremo de la privación de la libertad, cuando no de la vida de la persona secuestrada.

En el interior de las tiendas de electrodomésticos Elektra, asociada con Western Union y específicos con otros negocios menores y de ámbito local, los migrantes internacionales y sus familias pueden realizar operaciones de envío y cobro de remesas. Para octubre de 2006 dicha empresa contaba con una amplísima red con 1,569 locales en México, 74 en Guatemala, 70 en Honduras, 30 en Panamá y 81 en Perú, con ambiciosos planes de expansión en los países citados y otros del entorno regional.

\section{EL CORREDOR MEXICANO EN LA REGIÓN EU-CA Y ALLENDE}

Las evidencias empíricas aquí analizadas permiten señalar la existencia de una gran región con flujos migratorios que van de Centroamérica a Estados Unidos, con México como un estratégico espacio o corredor internacional, es decir, la articulación de los espacios de origen, tránsito y destino de la migración centroamericana indocumentada. En el espacio de tránsito se observa una diversificación de flujos y rutas con la participación muy dinámica y creciente de actores sociales e institucionales de distinto tipo, con actuaciones legales y no, con pesos relativos en lo nacional, regional y local mexicanos que generan tensiones, un pragmatismo institucional y sin duda importantes contradicciones en la política migratoria mexicana. Todo se mueve, menos el marco legal; todo va rápido, menos la actuación gubernamental; los distintos actores sociales innovan (aunque se equivoquen, luego procuran enmendar), mientras que las instancias migratorias nacionales reiteran la política migratoria errada (aunque lo sepan). Grave.

La articulación de los tres espacios (origen-tránsito-destino) muestra un proceso internacional cada vez más consolidado y boyante, aunque en este artículo se ha hecho hincapié en elementos sociales, institucionales y de política pública que ocurren en el interregno mexicano. Pero, justamente al presentar y dimensionar los distintos procesos que en éste ocurren, se explica con elementos comprobables, ya no sólo teóricos, la concurrencia de distintas formas de globalización acotada. Así, están los esfuerzos de coordinación que realizan los gobiernos del norte, Centroamérica y Caribe mediante, por ejemplo y entre otros instrumentos, la Conferencia Regional de Migración (que viene sesionando dos veces por año desde 1996); está la red financiera de remesas que vincula, al menos para este caso, Estados Unidos, México, Centroamérica, Caribe y tierras andinas; están las redes de tráfico de migrantes y trata de personas, con ramificaciones que van más allá del suelo continental americano; están las redes humanitarias que conectan los espacios geográficos de los migrantes; están, igualmente, las redes sociales y familiares de los propios migrantes, que enlazan entornos cada día más amplios y diversos; y están las redes virtuales que conectan a todos, instituciones, organismos civiles y migrantes. خCambiamos, innovamos, ampliamos el horizonte o seguimos con la inercia? 